\title{
Mouth-Opening Exercise and Patient Control Use of NSAIDs: Preliminary Study of Disk Displacement without Reduction
}

\author{
Tsuyoshi Tajima ${ }^{1}$, Kenichi Kurita $^{1}$, Hidemichi Yuasa $^{2}$, Nobumi Ogi ${ }^{1}$, Kouta Fukuta $^{1}$, Eri \\ Umemura $^{1 *}$, Masahiro Izumi ${ }^{4}$ and Garry V Brillo ${ }^{4}$ \\ ${ }^{1}$ Department of Oral and Maxillofacial Surgery, School of Dentistry, Aichi-Gakuin University, Japan \\ ${ }^{2}$ Department of Oral and Maxillofacial Surgery, Toyohashi Medical Center \\ ${ }^{3}$ Department of Maxillofacial Radiology, School of Dentistry, Aichi-Gakuin University \\ ${ }^{4}$ Oral Medicine Clinic, Lung Center of the Philippines, Quezon Avenue, Quezon City 1104, Philippines
}

Received: November 08 2013; Accepted: November 21, 2013, Published: December 14, 2013

*Corresponding author: Eri Umemura, Department of Oral and Maxillofacial Surgery, School of Dentistry, Aichi-Gakuin University, 2-11 Suemori-dori, Chikusa-ku, Nagoya 464-8651, Japan, E-mail: erimakilondon@hotmail.com

\begin{abstract}
Objectives: Our previous randomized study showed mouthopening exercises with nonsteroidal anti-inflammatory drugs (NSAIDs) therapy to be effective for temporomandibular joint (TMJ) pain and trismus in cases of disk displacement without reduction [1]. The purpose of this study is to determine whether mouth-opening exercises alone without NSAIDs can improve TMJ pain and trismus and to identify which patient requires supplemental administration of NSAIDs during treatment.
\end{abstract}

Methods: Eighty patients with unilateral TMJ pain and trismus were instructed to perform mouth-opening exercises under a patient controlled use of NSAIDs for 1 week. The patients who took NSAIDs were compared with those who were treated with TMJ exercises alone.

Results: Out of the 80 patients who performed mouth-opening exercises, 19 (24\%) took NSAIDs while the remaining 61 patients $(76 \%)$ did not take any pain medications. Two of the patients who took analgesics complained of stomach pain. It was noted that patients had reduced pain with mandibular movements and regained normal function during the study. Significant improvement on maximum mouth opening and quality of life was observed on both groups of patients. Improvement rate in patients who took NSAIDs were higher (37\%) than those who did not (26\%). Patients with smaller maximum mouth opening significantly took pain medications. Degree of pain on chewing before and after treatment was significantly larger in patients who took NSAIDs than those who did not. However, in total only 23 out of the 80 patients (29\%) improved based on the classification of TMJ dysfunction criteria for one week.

Conclusions: This study showed that mouth-opening exercises alone can improve TMJ pain and trismus but the need for NSAIDs was unavoidable in cases where symptoms were severe. The treatment regimen of mouth-opening exercises and minimal NSAIDs administration is recommended as a primary treatment for patients with TMJ pain and trismus in cases of disk displacement without reduction. More invasive secondary treatment is recommended for the patients who do not improve after the initial primary treatment.

Keywords: Disk displacement; Mouth-opening excises; Dysfunction

\section{Abbreviations}

NSAIDs: Non Steroidal Anti-Inflammatory Drugs; TMJ: Temporo-Mandibular Joint

\section{Introduction}

The main symptoms of Temporo-Mandibular Joint (TMJ) disk displacement without reduction are commonly pain and trismus $[2,3]$. Various treatments such as nonsteroidal anti-inflammatory drugs (NSAIDs) [4-6], splint use, mouth-opening training $[7,8]$, and arthrocentesis [8,9] have been reported to be effective in this condition $[4,10-16]$, but no protocol has been reported yet to established which treatment should be done first. We reported that the natural improvement rate over 6 months is sixteen percent (16\%) [18]. The primary treatment should be less invasive and yet deliver better results within a shorter period as compared to the natural course.

Our previous randomized study showed that combination of NSAIDs and mouth-opening exercises is effective for TMJ pain and trismus in cases of disk displacement without reduction [1]. In another study, A randomized clinical trial by Haketa [19] also showed that mouth-opening exercise significantly improved not only limitation of mouth opening but also TMJ pain in disk displacement without reduction. If the need for taking NSAIDs is reduced, the side effects of NSAIDs also decrease. Based on the previous studies, NSAIDs therefore might not be necessary during primary treatment of TMJ disk displacement without reduction accompanying TMJ pain and trismus. The purpose of this study is to determine whether mouth-opening exercises alone without NSAIDs can improve TMJ pain to identify which patient requires supplemental administration of NSAIDs during treatment.

\section{Subjects and Methods}

\section{Classification and clinical evaluation of TMJ dysfunction}

At the TMD clinic of Aichi-Gakuin University, we categorized 
and assessed patients based on the following classification. The degree of TMJ dysfunction was based on the measurement of maximum mouth opening and self-assessment of symptoms using four measures on TMJ visual analog scales (VASs) and MRI (Magnetic Resonance Imaging) evaluation. The degree of TMJ dysfunction was also classified into "none", "slight", "moderate", or "severe" as described in (Table 1). This classification is a modification of the TMJ criteria of the International Association of Oral and Maxillofacial Surgeons (IAOMS) and the American Association of Oral and Maxillofacial Surgeons (AAOMS) $[19,20]$. Pain at rest, pain on mandibular motion, pain on chewing, and intensity of interference in daily life were self-recorded individually by patients. The worst rating among the four scales and limitation of mouth opening were used to classify the degree of TMJ dysfunction. The measurement of maximum mouth opening, MRI evaluation, classification of the degree of TMJ and TMJ treatment were all performed by one different doctor who was one of our authors, T.T., M.I, K.K. and K.F. respectively.

\section{Subjects}

Inclusion criteria: Patients were selected on the basis of the following inclusion criteria: (1) pain on mandibular motion and pain on chewing in the unilateral TMJ region with VAS score $>34$; (2) maximal mouth opening <35 mm; and (3) magnetic resonance imaging (MRI) showing TMJ disk displacement without reduction. The classification was based on the preexisting condition prior to any form of treatment.

The following exclusion criteria were applied: (1) patients whose age is $<15$ or $\geqq 71$ years old; (2) patients with history of mandibular fracture; (3) patients with skin disease in TMJ region; (4) patients undergoing treatment with oral administration of NSAIDs or any other treatment within the past 2 weeks; (5) patients with history of digestive bleeding, heart disease, lung disease, renal disease, or other severe systemic diseases; (6) patients with history of drug hypersensitivity; (7) patients who are pregnant or breastfeeding; and (8) patients deemed medically that drug interaction with NSAIDs might occur.

Recruitment: Once the criteria on eligibility have been checked, patients, who visited the TMD clinic between March 2009 and May 2010, were invited to join the study.

Informed consent: All subjects read and understood all the information about the study and signed the informed consent

\begin{tabular}{|c|c|c|}
\hline $\begin{array}{c}\text { Degree of TMJ } \\
\text { dysfunction }\end{array}$ & $\begin{array}{c}\text { Maximal mouth } \\
\text { opening (mm) }\end{array}$ & $\begin{array}{c}\text { Maximum value on } \\
\text { any of 4 VASs (range } \\
\mathbf{0 - 1 0 0}\end{array}$ \\
\hline None & $\geq 40$ & 0 \\
\hline Slight & $35-39$ & $1-33$ \\
\hline Moderate & $30-34$ & $34-66$ \\
\hline Severe & $29-0$ & $67-100$ \\
\hline
\end{tabular}

Table 1: Classification of TMJ dysfunction.

Degree of TMJ dysfunction based on the worst value of maximal mouth opening and any of the 4 VASs. form before enrollment. This study was approved by the Ethics Committee on Human Researchof Aichi-Gakuin University School of Dentistry(Approval no.: 160).

\section{Treatment}

Patients were instructed to perform mouth-opening exercises and were given supplemental dose of orally administered NSAID (amfenac sodium $50 \mathrm{mg}$ ) when TMJ pain became unbearable for 1 week. The judgment whether pain is unbearable or not was entirely subjective to the patient. Potential adverse effects of NSAIDs were explained to the patients. Subjects were allowed to take the pain medication at a maximal allowed administration frequency of 4 times daily when the patient couldn't endure TMJ pain. And they were divided into two groups, patients who took NSAIDs and did not. For the mouth-opening exercises, the thumb was placed on the maxillary anterior teeth and the forefinger on the mandibular anterior teeth, which openedthe mouth manually and was asked to hold it at maximum opening for 10 seconds repeatedly 10 times. Participants were advised to achieve the maximum mouth opening at $35 \mathrm{~mm}$. The exercise was performed 4 times daily, 30 min after each meal and during bath for 1 week.

\section{Analysis}

Data collection: All patients recorded their maximal mouth opening and VAS scores upon study entry and one week later.

Data analysis: The results of the criteria for TMJ dysfunction namely: "Maximal mouth opening" (mm) and VAS scores for "pain at rest", "pain on mandibular motion", "pain on chewing", and "interference in daily life" were analyzed statistically using the Student's t-test. Patients who had "no" or "slight" TMJ dysfunction during last follow-up were classified as improved while those with "moderate" or "severe" TMJ dysfunction at the last follow-up were classified as no improvement. Improvement rates at 1 week were calculated by dividing the number of improved patients by the total number of enrolled patients.

The patients were divided into two groups: "with NSAIDs" and "without NSAIDs" and were analyzed based on the characteristics of each group. The pre-treatment and post-treatment values for "maximal mouth opening", "pain at rest", "pain on mandibular motion", "pain on chewing", "interference in daily life", and "degree of dysfunction" were compared statistically by Student's t-test; P values less than 0.05 were considered significant. Changes of these values from start of study up to a period of 1 week were compared between the two groups.

\section{Results}

Eighty patients (M/F, 8/72; mean age, $40.3 \pm 16.6$ years) with disk displacement without reduction as shown by the MRI were selected based on our inclusion criteria and agreed to join the study.

When the values of the 80 patients were compared before and after the treatment, significant improvement was noted in all 4 following criteria: maximal mouth opening, pain on mandibular 
motion, pain on chewing, and interference in daily life (Table 2) At the start of the study, twenty-five patients were classified as having moderate TMJ dysfunction and 55 as severe TMJ dysfunction. After a week of treatment, 23 were classified with slight dysfunction, 20 with moderate dysfunction, and 37 with severe dysfunction. The improvement rate was 29\% (Table 3).

Of the 80 patients, 19 patients (24\%) took NSAIDs and the remaining 61 patients $(76 \%)$ didn't take any pain medication. NSAIDs were taken 1-22 times, with an average of 8.1 times during the treatment. Two patients who took NSAIDs had stomach discomfort and were noted as an adverse effect. The values were compared between patients who took NSAIDs and those who did not. Both groups showed significant improvement in maximal mouth opening, pain on mandibular motion, pain on chewing, and interference in daily life for 1 week (Table 4). Maximal mouth opening before treatment was significantly lower in patients who took NSAIDs compared with those who did not take NSAIDs (Table 5). The mean age of patients who took NSAIDs was also significantly older than those who did not take the medicine ( $47.7 \pm 16.4$ vs. $38.0 \pm 16.1$ years). The decrease in values of pain on chewing before and after treatment was significantly larger in patients who took NSAIDs than those who did not (Table 6). Even though there was no statistical significance, it is worth mentioning that the improvement rate for patients who took NSAIDs was higher at $37 \%$ than those patients who did not take NSAIDs at $26 \%$ (Table7).

\section{Discussion}

In this study, only 19 out of 80 patients took NSAIDs

\begin{tabular}{|c|c|c|c|}
\hline & $\begin{array}{c}\text { Before } \\
\text { treatment }\end{array}$ & After treatment & p-value \\
\hline $\begin{array}{c}\text { Maximal mouth } \\
\text { opening (mm) }\end{array}$ & 28 & 31 & $0.00^{*}$ \\
\hline $\begin{array}{c}\text { Pain at rest } \\
\text { (VAS) }\end{array}$ & 17 & 15 & 0.08 \\
\hline $\begin{array}{c}\text { Pain on } \\
\text { mandibular } \\
\text { motion (VAS) }\end{array}$ & 56 & 40 & $0.00^{*}$ \\
\hline $\begin{array}{c}\text { Pain on chewing } \\
\text { (VAS) }\end{array}$ & 51 & 35 & $0.00^{*}$ \\
\hline $\begin{array}{c}\text { Interference in } \\
\text { daily life (VAS) }\end{array}$ & 41 & 31 & $0.00^{*}$ \\
\hline
\end{tabular}

Table 2: Changes in TMJ dysfunction in all patients before and after treatment. Average VAS score $(0-100) .{ }^{*} \mathrm{P}<0.05$ (Student's t-test).

\begin{tabular}{|c|c|c|c|}
\hline \multirow{2}{*}{$\begin{array}{l}\text { Degree of TMJ } \\
\text { dysfunction }\end{array}$} & \multicolumn{2}{|c|}{ No. patients (\%) } & \\
\hline & $\begin{array}{c}\text { Before } \\
\text { treatment }\end{array}$ & After treatment & \\
\hline None & - & - & Improved \\
\hline Slight & - & $23(29 \%)$ & $29 \%$ \\
\hline Moderate & $25(31 \%)$ & $20(25 \%)$ & Not improved \\
\hline Severe & $55(69 \%)$ & 37 (46\%) & $71 \%$ \\
\hline Total & $80(100 \%)$ & $80(100 \%)$ & \\
\hline
\end{tabular}

Table 3: Changes in TMJ dysfunction in total patients.

\begin{tabular}{|c|c|c|c|}
\hline $\begin{array}{l}\text { Patients who } \\
\text { took NSAIDs }\end{array}$ & $\begin{array}{c}\text { Before } \\
\text { treatment }\end{array}$ & After treatment & p-value \\
\hline $\begin{array}{c}\text { Maximal mouth } \\
\text { opening }(\mathrm{mm})\end{array}$ & 26 & 32 & $0.00^{*}$ \\
\hline $\begin{array}{l}\text { Pain at rest } \\
\text { (VAS) }\end{array}$ & 14 & 15 & 0.52 \\
\hline $\begin{array}{c}\text { Pain on } \\
\text { mandibular } \\
\text { motion (VAS) }\end{array}$ & 56 & 41 & $0.00^{*}$ \\
\hline $\begin{array}{c}\text { Pain on chewing } \\
\text { (VAS) }\end{array}$ & 59 & 35 & $0.00^{*}$ \\
\hline $\begin{array}{l}\text { Interference in } \\
\text { daily life (VAS) }\end{array}$ & 43 & 32 & $0.00 *$ \\
\hline $\begin{array}{l}\text { Patients who } \\
\text { did not take } \\
\text { NSAIDs }\end{array}$ & $\begin{array}{c}\text { Before } \\
\text { treatment }\end{array}$ & After treatment & p-value \\
\hline $\begin{array}{c}\text { Maximal mouth } \\
\text { opening }(\mathrm{mm})\end{array}$ & 28 & 32 & $0.00^{*}$ \\
\hline $\begin{array}{l}\text { Pain at rest } \\
\text { (VAS) }\end{array}$ & 18 & 15 & 0.15 \\
\hline $\begin{array}{c}\text { Pain on } \\
\text { mandibular } \\
\text { motion (VAS) }\end{array}$ & 56 & 41 & $0.00^{*}$ \\
\hline $\begin{array}{c}\text { Pain on chewing } \\
\text { (VAS) }\end{array}$ & 49 & 35 & $0.00^{*}$ \\
\hline $\begin{array}{l}\text { Interference in } \\
\text { daily life (VAS) }\end{array}$ & 41 & 32 & $0.00^{*}$ \\
\hline
\end{tabular}

Table 4: Changes in TMJ dysfunction over the 1-week treatment period in patients who took NSAIDs and did not.

\begin{tabular}{|c|c|c|c|}
\hline & Without NSAIDs & With NSAIDs & p-value \\
\hline $\begin{array}{c}\text { Maximal mouth } \\
\text { opening (mm) }\end{array}$ & 28 & 26 & $0.02^{*}$ \\
\hline $\begin{array}{c}\text { Pain at rest } \\
\text { (VAS) }\end{array}$ & 18 & 14 & 0.55 \\
\hline $\begin{array}{c}\text { Pain on } \\
\text { mandibular } \\
\text { motion (VAS) }\end{array}$ & 56 & 56 & 0.96 \\
\hline $\begin{array}{c}\text { Pain on chewing } \\
\text { (VAS) }\end{array}$ & 49 & 59 & 0.07 \\
\hline $\begin{array}{c}\text { Interference in } \\
\text { daily life (VAS) }\end{array}$ & 41 & 43 & 0.78 \\
\hline $\begin{array}{c}\text { Average age } \\
\text { (years) }\end{array}$ & 38 & 48 & $0.03^{*}$ \\
\hline
\end{tabular}

Table 5: Value differences before treatment between patients who took NSAIDs and did not. Average VAS score $(0-100) .{ }^{*} \mathrm{P}<0.05$ (Student's t-test).

\begin{tabular}{|c|c|c|c|}
\hline & Without NSAIDs & With NSAIDs & p-value \\
\hline $\begin{array}{c}\text { Maximal mouth } \\
\text { opening (mm) }\end{array}$ & 29 & 26 & 0.20 \\
\hline $\begin{array}{c}\text { Pain at rest } \\
\text { (VAS) }\end{array}$ & 15 & 12 & 0.68 \\
\hline $\begin{array}{c}\text { Pain on } \\
\text { mandibular } \\
\text { motion (VAS) }\end{array}$ & 50 & 51 & 0.34 \\
\hline $\begin{array}{c}\text { Pain on chewing } \\
\text { (VAS) }\end{array}$ & 45 & 54 & $0.02^{*}$ \\
\hline $\begin{array}{c}\text { Interference in } \\
\text { daily life (VAS) }\end{array}$ & 40 & 42 & 0.40 \\
\hline
\end{tabular}

Table 6: Value differences between before and after treatment. Average VAS score $(0-100) .{ }^{*} \mathrm{P}<0.05$ (Student's t-test). 


\begin{tabular}{|c|c|c|c|}
\hline \multirow{2}{*}{$\begin{array}{l}\text { Degree of TMJ } \\
\text { dysfunction }\end{array}$} & \multicolumn{2}{|c|}{$\begin{array}{c}\text { No. patients who took NSAIDs } \\
(\%)\end{array}$} & \\
\hline & $\begin{array}{l}\text { Before } \\
\text { treatment }\end{array}$ & After treatment & \\
\hline None & - & - & Improved \\
\hline Slight & - & $7(37 \%)$ & $37 \%$ \\
\hline Moderate & $3(16 \%)$ & $3(16 \%)$ & Not improved \\
\hline Severe & $16(84 \%)$ & $9(47 \%)$ & $63 \%$ \\
\hline Total & $19(100 \%)$ & $19(100 \%)$ & \\
\hline \multirow{2}{*}{$\begin{array}{l}\text { Degree of TMJ } \\
\text { dysfunction }\end{array}$} & \multicolumn{2}{|c|}{$\begin{array}{c}\text { No. patients who took NSAIDs } \\
(\%)\end{array}$} & \\
\hline & $\begin{array}{l}\text { Before } \\
\text { treatment }\end{array}$ & After treatment & \\
\hline None & - & - & Improved \\
\hline Slight & - & $16(26 \%)$ & $26 \%$ \\
\hline Moderate & $22(36 \%)$ & $17(28 \%)$ & Not improved \\
\hline Severe & $39(64 \%)$ & $28(46 \%)$ & $74 \%$ \\
\hline Total & $61(100 \%)$ & $61(100 \%)$ & \\
\hline
\end{tabular}

Table 7: Changes in TMJ dysfunction in patients who took NSAIDs and did not.

intermittently only as needed. Both groups that did mouthopening exercise improved their maximal mouth openings, reduced pain on mandibular motion and chewing and interference in daily life, whether they took NSAIDs or not. Additionally, patients who took NSAIDs had significantly smaller maximal mouth opening before treatment than those who did not take analgesics. On the other hand, pain on chewing significantly decreased to a greater degree in patients who took NSAIDs than in those who did not. Therefore, patients with severe symptoms tend to take supplemental NSAIDs. Additional administration of NSAIDs together with mouth-opening exercise further reduces TMJ pain and trismus. This study, however, could not determine whether any correlation exists between quantity of NSAIDs taken and degree of TMJ dysfunction because of its small sample size. Further studies are needed to determine whether the amount of NSAIDs taken relates to the level of improvement in TMJ dysfunction.

It is also an interesting discussion point whether only mouth opening exercise improves TMJ pain and trismus. There were not any differences in the degree of TMJ dysfunction between the groups that took NSAIDs or not. Chi-square test was performed to determine if there are any other differences between these groups. The improvement rate for patients who did not take NSAIDs was twenty six percent, which is higher than the natural improvement rate $(16 \%)$ over 6 months in our previous study [18]. A randomized clinical trial by Haketa [19] also showed that mouth-opening exercise significantlyimproved not onlylimitation of mouth opening but also TMJ pain in disk displacement without reduction. Nitzan [21] likewise reported that limitation of TMJ movement is caused by lubricant impairment and improved by mouth-opening exercise. This study also showed that mouthopening exercise without taking NSAIDs is effective for patients with limited pretreatment mouth opening range.
In this study, only 19 of 80 patients (24\%) took the NSAIDs.It is thought that potential adverse effects of NSAIDs can be avoided if patients were given controlled intake of analgesics because adverse effects were explained to them before starting treatment and intake is based on their own discretion. Amfenac sodium has been reported effective in alleviating TMJ pain but the incidence of adverse effects is high at 8-27\% [22-24]. Of the 19 patients who took NSAIDs, two patients (11\%) had stomach discomfort as an adverse effect. Although the incidence rate of adverse effects in the 19 patients was within the range of previous reports, it is helpful to understand that the incidence rate in our sample was actually reduced to $3 \%$ in the total 80 patients. Therefore, we consider it important to reduce incidence of adverse effects by askingthe participants to take fewer NSAIDs as possible in the primary treatment for TMJ disk displacement without reduction.

The total improvement rate at $29 \%$ is not that high. But comparing the natural improvement rate of 16\%over 6 months of our previous study [18] with the results of study having a shorter period of 1 week, we think that this improvement rate is acceptable. For unimproved cases using this treatment regimen, secondary treatment such as continuous administration of NSAIDs with mouth-opening exercise and other surgical treatments were applied.

This study was not a randomized clinical trial but was based on our previous randomized study [10] that showed that mouthopening exercise under continuous use of NSAIDs is effective for patients with disk displacement without reduction. This is the first report in which NSAIDs were used intermittently only when TMJ pain was unbearable. Because this paper demonstrates that mouth-opening exercise under patient controlled use of NSAIDs are effective for some patients with TMJ disk displacement without reduction, we can proceed to our next randomized study comparing the different treatment modalities including a group under combination therapy with another group performing mouth-opening exercise alone or with NSAIDS and a group with no treatment. In this study, we found that subjects of older age and lower maximal mouth openings tend to need NSAIDs along with mouth-opening exercise. This finding can help us more likely to prescribe NSAIDs and explain that they are helpful for pain relief for those patients in dental practice.

In some cases, mouth-opening exercises alone reduces TMJ symptoms. However, the use of NSAIDs still play a vital role in controlling discomfort and improving function of patients in more severe conditions. Based on our results, we can conclude that mouth-opening exercises combined with patient controlled use of NSAIDs for 1 week can be an effective primary treatment in patients with TMJ pain and trismus caused by disk displacement without reduction.

\section{Conclusion}

This study showed that mouth-opening exercises alone can improve TMJ pain and trismus but the need for NSAIDs was unavoidable in cases where symptoms were severe. 
The treatment regimen of mouth-opening exercises and minimal NSAIDs administration is recommended as a primary treatment for patients with TMJ pain and trismus in cases of disk displacement without reduction. More invasive secondary treatment is recommended for the patients who do not improve after the initial primary treatment.

\section{References}

1. Yuasa, H. \& Kurita, K. (2001). Randomized clinical trial of primary treatment for temporomandibular joint disk displacement without reduction and without osseous changes: a combination of NSAIDs and mouth-opening exercise versus no treatment. Oral Surg Oral Med Oral Pathol Oral Radiol Endod, 91, 671-675.

2. Abe, Y., Kataoka, R., Funato, M. \& Furuya, R. (2006). A clinical study of patients with temporomandibular disorders at temporomandibular disorder clinic from September 2004 to August 2005. J Showa Dent, $26,241-247$

3. Kurita, K., Wetersson, P., Yuasa, H., Sotoyama, M., et al. (1993). Clinical observation of closed lock: natural course of untreated symptoms after 6 and 12 months. JJpn Soc TMJ, 5, 415-426.

4. Hattori, Y., Kurita, K., Nakajima, K., Wakita, S., Nakatsuka, K., Shimizu, M., et al. (2009). Mouth opening exercises with NSAIDs for temporomandibular joint disk displacement with reduction associated with pain and trismus. J Dent Aichi-Gakuin Univ, 47, 455-462.

5. Kurita, K. (2001). Evidence based drug therapy for temporomandibular disorders. Clinic Dent Res, 1 (1), 23-27.

6. Sugisaki, M., Kakudo, K., Ohura, K., \& Okabe, S., (2001). Sensitivity of NSAID efficacy evaluation criteria for temporomandibular disorders. $J$ Jpn Assoc Dent Sci, 29, 47-51.

7. Haketa, T., Kino, K., Sugisaki, M., Takaoka, M. \& Ohta, T. (2010). Randomized Clinical Trial of Treatment for TMJ Disc Displacement. $J$ Dent Res, 89(11), 1259-1263.

8. Nitzan, D.W. (2001). The process of lubrication impairment and its involvement in temporomandibular joint disc displacement: A theoretical concept. J Oral Maxillofac Surg, 59, 36-45.

9. Davies, S.J., Gray, R.J. (1997). The pattern of splint usage in the management of common temporomandibular disorders. Part I. The anterior repositioning splint in the treatment of disc displacement with reduction. Br Dent J, 183(6), 199-203.

10. Lundh, H., Westesson, P.L., et al. (1992). Temporomandibular joint disk displacement without reduction: Treatment with flat occlusa splint versus no treatment. Oral Surg Oral Med Oral Pathol, 73(6), 655-658.

11. Yuasa, H., Kurita, K., et al. (1997). Preliminary study of primary treatment for temporomandibular joint disk displacement without reduction associated with arthritis. JJpn Soc, TMJ 9, 491-499.
12. Chung, S.C. \& Kim, H.S. (1993). The effect of the stabilization splint on the TMJ closed lock. Cranio, 11(2), 95-101.

13. Nitzan, D.W., Price, A.P., (2001). The use of arthrocentesis for the treatment of osteoarthritis temporomandibular joints. J Oral Maxillofac Surg, 59, 1154-1159.

14.Fukuta, K., \& Kurita, K. (2002). Primary treatment for temporomandibular joint osteoarthritis: combination therapy with two consecutive arthrocentesis followed by non-steroidal antiinflammatory drug administration. J Jpn Oral Maxillofac Surg, 48, 520-525.

15. Nakatsuka, K., \& Kurita, K. (2004). Primary treatment for temporomandibular joint osteoarthritis: combination therapy with two consecutive arthrocentesis followed by mouth opening exercises and non-steroidal anti-inflammatory drug administration. J Jpn Oral Maxillofac Surg, 50, 577-784.

16. Wakita, T., Kurita, K., Ogi, N., Shimizu, M., Nabeshima, H., Yajima, T., et al. (2006). Primary treatment for temporomandibular joint osteoarthritis: combination therapy with two consecutive arthrocenteses (steroid injection) followed by mouth opening exercises and non-steroidal anti-inflammatory drug administration. $J$ Jpn Oral Mxillofac Surg, 52, 480-488.

17.Wakita, T., Kurita, K., Nakatsuka, K., \& Ogi, N. (2010). Effect of intracapsular steroid injection in combination with arthrocentesis followed by mouth opening exercises and non-steroidal antiinflammatory drug treatment for closed lock. J Jpn Oral Maxillofac Surg, 56, 298-304.

18. Dimitroulis, G. (2011). Temporomandibular joint surgery: what does it mean to the dental practitioner? Aust Dent J, 56, 257-264.

19. Kurita, K., Westesson, P. L., Yuasa, H., Toyama, M., Machida, J., \& Ogi, N. (1998). Natural course of untreated symptomatic temporomandibular joint disc displacement without reduction. J Dent Res, 77, 361-365.

20. Ad Hoc Study Group on TMJ Meniscus Study: 1984 Criteria for TMJ meniscus surgery. AAOMS, November 1, 1984.

21.Goss, A. N. (1993). Toward an international consensus on temporomandibular joint surgery. Int J Oral Maxillofac Surg, 22, 7881.

22. Kakudo, K., Ishibashi, K., Ohura, K., Okabe, S., Kino, K., Kurita, K., et al. (2007). The classification of non-steroidal anti-inflammatory drug, effect for temporomandibular joint pain. Drug Therapy, 26, 44-54.

23. Shibata, T., Kizuno, N., Oniya, N., Yonetsu, H., Takano, N., Sato, K., et al. (1998). The clinical evaluation of Amfenac Sodium (Fenazox®) for temporomandibular disorders. JJpn Oral Maxillofac Surg, 27, 242-263.

24.Kino, K., Tei, K., Nakai, N., Waki, H., Izumi, H., Omura, K., et al. (1988). The clinical evaluation of Amfenac Sodium (Fenazox ${ }^{\circledR}$ ) for temporomandibular disorders. JJpn Oral Maxillofac Surg, 37, 242-263. 